
ресурсным обеспечением инновационной деятельности

\begin{tabular}{|c|c|}
\hline $\begin{array}{l}\text { М. С. Асмолова }{ }^{1} \\
\text { С. В. Дедов } 1\end{array}$ & $\begin{array}{l}\text { asmolova.m.s@gmail.com } \\
\text { generdeser@bk.ru }\end{array}$ \\
\hline \multicolumn{2}{|c|}{$\begin{array}{l}1 \text { кафедра управления, организации производства и отраслевой экономики, Воронеж. гос. ун-т. инж. техн., пр-т Революции, 19, г. } \\
\text { Воронеж, 394066, Россия }\end{array}$} \\
\hline $\begin{array}{l}\text { Реферат. Исследования экономики знаний обусловлены актуализацией ро } \\
\text { институализация управлением ресурсным обеспечением направлено на пре } \\
\text { вития. Важным научным направлением является проведение теоретическог } \\
\text { ления, развития и совершенствования. Данное утверждение определило нео } \\
\text { ституализации форм управления ресурсным обеспечением инновационной д } \\
\text { ходов по различным параметрам на основе анализа большого количества ис } \\
\text { тия институализация, как определяемого феномена во временной перспекти } \\
\text { ными исследования из разных периодов развития экономической науки. П } \\
\text { научных исследований позволил сделать вывод, что знание и информацию след } \\
\text { фактора производства. Отдельно проанализировано влияние процессов глобали } \\
\text { делено в отдельный бок исследование проблем инновационного развития } \\
\text { ствует повышению конкурентоспособности национальной экономики и тор } \\
\text { новационной системы, сдерживая переход к инновационной модели развити } \\
\text { номической глобализации роль новых информационных технологий и форм } \\
\text { мечен тот факт, что если ранее наука развивалась в направлении углубле } \\
\text { то в предстоящее столетие должно произойти углубление знаний на основе }\end{array}$ & $\begin{array}{l}\text { лиза экономических ресурсов в контексте их появ- } \\
\text { Імость рассмотрения теоретического подхода к ин- } \\
\text { пнов. Проанализированы особенности самого поня- } \\
\text { качестве анализа использованы проведенные уче- } \\
\text { енный анализ многочисленных профессиональных и } \\
\text { ассматривать в качестве нового вида экономического } \\
\text { п, затронувшие научно-инновационную сферу. Вы- } \\
\text { Ійской экономики, нерешенность которых препят- } \\
\text { г формирование региональной и национальной ин- } \\
\text { иведена в качестве доказательства углубления эко- } \\
\text { ание единого информационного пространства. От- } \\
\text { наний на основе общественного разделения наук, } \\
\text { обществления. }\end{array}$ \\
\hline
\end{tabular}

\title{
Theoretical approach to the institutionalization of forms of governance resource provision of innovative activity
}

\begin{tabular}{l} 
P. M. Asmolova 1 asmolova.m.s@gmail.com \\
\hline management, organization of production and branch economy department, Voronezh state university of engineering technologies, \\
Revolution Av., 19 Voronezh, 394066, Russia \\
Summary. Knowledge economy research due to the actualization of the role of knowledge and information. Management, its impact and the \\
institutionalization of management resource provision designed to overcome the problems inherent in the present stage of development. An \\
important research direction is to carry out theoretical analysis of economic resources in the context of their occurrence, development and \\
improvement. This assertion has identified the need to consider the theoretical approach to the institutionalization of forms of resource man- \\
agement software innovation and analysis and typology of approaches by different parameters on the basis of analysis of a large number of \\
sources. The features of the concept of institutionalization as defined phenomenon in a time perspective. In an analysis conducted by scientists \\
used studies from different periods in the development of economic science. The analysis of numerous professional and scientific research led \\
to the conclusion that knowledge and information should be dis-regarded as a new type of economic production factors. Separately, analyzed \\
the impact of globalization processes that have affected the scientific and innovative sphere. Allocated to a separate study by side issues of \\
innovative development of the Russian economy, which prevents the unresolved improve the competitiveness of the national economic and \\
inhibits the formation of regional and national innovation system, restraining the transition to an innovative model of development. Citing as \\
evidence of the deepening of economic globalization, the role of new information technologies and the formation of a single information space. \\
Noting the fact that if the earlier science developed to deepen knowledge on the basis of the social division of Sciences, in the coming century \\
should happen deepening of knowledge on the basis of their socialization. \\
Keywords: institutionalization, resource provision, innovation resources, innovation \\
\hline \hline
\end{tabular}

\section{Введение}

Актуальность рассуждений о методологических ориентирах изучения инновационных процессов обусловлена быстротой меняющихся экономических отношений и развитием научного аппарата экономических дисциплин. Проведенный анализ публикаций, посвященных проблеме интенсификации вовлечения результатов интеллектуальной деятельности человека во всех областях экономики, позволил сделать

\section{Для цитирования}

Асмолова М. С., Дедов С. В. Теоретический подход к институциализации форм управления ресурсным обеспечением инновационной деятельности // Вестник ВГУИТ. 2016. № 4. С. 422-426. doi:10.20914/2310-1202-2016-4-422-426 вывод об актуальности проводимого исследования. Тезис о желании достижения первенства в перспективных отраслях народного хозяйства сделан на основании тенденций всех стран мира к укреплению научно-технического потенциала, расширению инвестиций в наукоёмкие технологии, сотрудничеству и ускорению темпов научнотехнологического развития.

В современных условиях экономический рост отождествляется с научно-техническим прогрессом и интеллектуализацией основных

For citation

Asmolova M. S., Dedov S. V. Theoretical approach to the institutionalization of forms of governance resource provision of innovative activity. Vestnik VSUET [Proceedings of VSUET]. 2016. no. 4. pp. 422-426. (in Russian). doi:10.20914/2310-1202-2016-4-422-426 
факторов производства. Важность исследования определяется непрерывным процессом закономерным развития понятийного и научного аппарата экономических дисциплин. Значительное количество публикаций, посвященных исследуемой проблеме не раскрывает многоаспектности проблемы формирования базисных теоретических подходов и продолжает быть актуальной научной темой. В то же время отмечено, что исследуемой проблеме в комплексе в научных изданиях уделяется недостаточное внимание.

Экономика XXI века базируется на знаниях и информации, ставших достоянием и используемых в практической деятельности экономически активного населения. Рассмотрены тенденции формирования новой «гуманистической экономики», ориентирующаяся на социум (общности, общество в целом) с новым «социальным способом производства», где человек - главный элемент, исходная и конечная цель общественного развития.

Это обусловлено особенностями информационно-технологической революции, формирующей экономику знаний. В результате знания и информация становятся важнейшими ресурсами инновационной деятельности. И мы считаем, что с их помощью удается преодолевать или смягчать демографические, трудовые, сырьевые, пространственные и временные, экологические и другие виды ресурсные обеспечения, обеспечивать эффективность управления и устойчивость процесса институализации. На основе сделанного вывода предложено уровень, тип, вид и количество опредмеченных (закодированных) в нём ресурсов положить в основу ценности того или иного экономического явления. В статье проанализирована зависимость категории «ресурс» от управленческого воздействия и, вследствие этого, зависимость имеет универсальный, междисциплинарный и многоаспектный характер и включается в понятийный аппарат многих областей знаний.

Основой и целью развития современной экономики являются накопление целесообразных знаний и информации и совершенствование форм их управления и средств их обработки и использования. С началом формирования экономики знаний и институтов для осуществления управлением инновационной деятельностью этот процесс проходил и характеризовался проблемностью и неоднозначностью. Однако весь комплекс проблем, связанных с необходимостью институализации, малоизучен современной наукой несмотря на традиционный подход к рассмотрению экономических ресурсов в контексте появления, развития и совершенствования. Данное утверждение определило необходимость рассмотрения теоретического подхода к институализации форм управления ресурсным обеспечением инновационной деятельности.
Характеристику данного понятия трактуют в течение длительного периода времени разные авторы, что обуславливает как возможность проведения анализа и типологизации подходов по различным параметрам на основе анализа большого количества источников, так и сложность, вследствие большого количества подходов и их неоднозначности.

Среди причин сложностей необходимо указать на ряд особенностей самого понятия институализация как определяемого феномена во взаимосвязи с необходимостью управления инновационной деятельностью и, как следствие, институализации самого управления:

- многоаспектность (качество результатов; качество возможностей использования, обеспечивающих результат; качество процесса, качество субъектов ими пользующимися);

- многосубъектность (индивид, структура, муниципальность или региональность, общество в целом, государственные органы, исследователи процесса и институтов, не включенные в нее непосредственно);

- многоуровневость (применимость ресурсов, управленческого воздействия различных ступеней);

- многокритериальность (оценивается различными субъектами по многочисленным наборам критериев);

- неопределенность (масштабность, неоднородность);

- полихронность (сочетание тактических и стратегические аспектов, которые в разное время с учетом приоритетов в содержании и форме различными субъектами могут восприниматься по-разному, а значит и по-разному трактоваться);

- вариативность и инвариантность (большая специфичность).

Анализ подходов к институализации форм управления ресурсным обеспечением инновационной деятельности, относится к 60-м годам. К этому периоду сформировались важнейшие методологические основы институализации форм управления ресурсным обеспечением инновационной деятельности с позиций прогресса науки и образования, всесторонне исследовалось качественное изменение места и роли знаний и информации в общественном производстве.

В 60-е и 70-е годы исследования Д. Белла, Г. Кана, К. Томинаги, Р. Дарендорфа и многих других авторов привели к глубокому осознанию радикально изменившегося характера самого процесса ресурсного обеспечения современного общества. Данные авторы считают, что в результате взаимодействия науки и производства уменьшилась восприимчивость техники к новым открытиям и изобретениям, технические задачи перестали стимулировать умножение научного знания. 
Отдельные направления исследуемой проблемы рассматривались российскими учёными Н. Бекетовым, В. Даниловым, Г. Кошевой, А. Козыревым, В. Макаровым, А. Сотсковым, В. Полтеровичем. Их теоретические изыскания свидетельствуют, что полезность знания возрастает небывалыми темпами. Знание стало ресурсом всякого производства, причем оно уже сегодня дает экономию труда значительно большую, чем затраты в науке на получение знания. Это подтверждают современные исследования процессов управления, охватывающие три стратегически взаимосвязанных группы - глобальные знания, локально-глобальные, а также сублокальные [1].

Ф. Махлуп воспринимал инновационную деятельность экономики знаний как важнейшее условие развития секторов экономики. Среди подобных теорий наиболее заметной стала концепция информационного общества. Введенный Т. Умесао термин «информационное общество» получил всемирное признание после выхода в свет знаменитой книги Й. Масуды и приобрело новое звучание в работах Т. Сакайи. Информационная экономика, как интегральная научная дисциплина имеет особый предмет, метод и инструментарий исследования.

Р. Арманном была сформулирована концепция обмена знаниями для достижения общего знания. Её главной идеей является утверждение, что информация, которую используют экономические субъекты не только различна по полноте и качеству, но и постоянно изменяется. Основой развития теории информационной экономики послужили: концепция аукционов «стратегиядоказательство» В. Викери.

Теория постиндустриального общества сформировалась в результате всестороннего анализа качественно новой ситуации, сложившейся в анализируемый период в развитых индустриальных странах. Именно на обнаружение характерных черт рождающегося нового общества и были направлены усилия основоположников теории «экономики, основанной на знаниях» T. Стюарта, Т. Сакайи, Н. Штера. Напротив, большинство американских и европейских исследователей, начиная со второй половины 80-х годов, стали акцентировать внимание на роли и значении не столько информации, сколько знания, что породило целый спектр новых определений современного общества, среди которых такие, как knowledge society, knowledgeable society и т. д.

Понимание того, что современное общество может, и должно рассматриваться именно как постиндустриальное, укрепляется по мере анализа логики развития цивилизации, какой она представлена в рамках постиндустриальной теории. Согласно теоретических изысканий её сторонников, в истории достаточно строго прослеживаются три большие эпохи, образующие триаду «доиндустриальное - индустриальное - постиндустриальное общество». Такая периодизация социального прогресса основана на нескольких критериях, а постиндустриальное общество противопоставляется индустриальному и доиндустриальному по трем важнейшим параметрам:

- основному производственному ресурсу (в постиндустриальном обществе ими являются знание и информация, в индустриальном - энергия и технологии, в доиндустриальном - первичные условия производства, сырье);

- типу производственной деятельности (он рассматривается в постиндустриальном обществе как последовательная обработка [processing] в противоположность изготовлению [fabrication] и добыче [extraction] на более ранних ступенях развития);

- характеру базовых технологий (определяющихся в постиндустриальном обществе как наукоемкие, в эпоху индустриализма - как капиталоемкие и в доиндустриальный период как трудоемкие).

Это позволяет сделать утверждение, что то, что мы знаем об экономических законах и категориях, не предел. Еще К. Маркс указывал на недопустимость брать экономические категории в той последовательности, в которой они исторически играли решающую роль. Их последовательность в системе определяется теми отношениями, в котором они находятся друг другу в данный период развития общества. В то же время понятие «экономические ресурсы» напрямую связаны с понятием «факторы производства». В отечественной экономической литературе термины «фактор» и «ресурс» используются по-разному.

Несмотря на множество разных подходов, большинство исследователей отмечают главное знание и информацию следует рассматривать в качестве нового вида экономического фактора производства [2]. Как факторы производства знания и информация имеют свойства, качественно отличающие их от других ресурсов производства: в них противоречиво сочетаются подлинная безграничность и редкость высшего уровня, объективный характер и беспрецедентный субъективизм, невоспроизводимость и тиражируемость. При этом, неэкономические мотивы деятельности людей, осваивающих этот ресурс, приводят к вполне экономическим, по своей сути, последствиям.

Современные процессы глобализации, затронувшие и научно-инновационную сферу, создают базу для международной интеграции в экономической, политической, социокультурной, экологической и других областях. В то же время становлению и формированию мировой интегрированной научно-инновационной системы присущи собственные закономерности и 
противоречия, которые неизбежно будут проявляться в российской практике [3]. Особенности, присущие процессу глобализации мировой экономики, предопределяют рассмотрение данных функций не опосредованно, а в достаточно сложной их взаимосвязи. По своей сути глобализация является высшей стадией интеграции. Она идет к расширению обмена материальными, интеллектуальными ценностями, а также знаниями и информацией.

$\mathrm{He}$ менее значимыми в современных условиях являются проблемы инновационного развития, нерешенность которых препятствует повышению конкурентоспособности национальной экономики и тормозит формирование региональной и национальной инновационной системы, сдерживая переход к инновационной модели развития.

Осмысление содержания и направленности управления инновационной деятельностью, с использованием знания и информации становится важной задачей. Неслучайно Б. Гейтс, основатель и глава Microsoft, сказал знаменитую фразу: «Люди склонны переоценивать то, чтослучится через шесть месяцев, но недооценивать то, что произойдет через шесть лет». Неравномерность распределения знаний в эпоху глобализации, как капитала, в индустриальный период ведёт к изменению условий, обуславливающих образование господствующей элиты и повышению способностей для всех людей воспринимать и порождать новые идеи.

Усиление глобализационных процессов предполагает формирование комплексной системы управления также и возможными рисками инновационной деятельности, способной адекватно, точно, своевременно и компетентно реагировать на вызовы, предугадывать и предотвращать потенциальные угрозы. Существующая степень неопределенности результатов инновационных процессов в современной экономике влияет на то, что любая преднамеренная деятельность предполагает непредсказуемость последствий использования эффективных инноваций и результатов их внедрения в рыночное производство [4].

Новые информационные технологии стали мощным инструментом распространения единых стандартов, выработки общих ценностей и целей, привели к формированию единого информационного пространства. Доказательством тому служат углубление экономической глобализации, оживленное развитие науки и техники, активное перемещение ресурсов и все более тесные экономические отношения между странами, появление новых институциональных форм управления. Появилась возможность управлять инновационной деятельностью: знания, информация, технологии в режиме реального времени на значительных расстояниях независимо от национальных границ.

Интерпретируя данный тезис применительно к региональной экономике, необходимо отметить, что региональная система в процессе своего развития: 1) находит новое состояние равновесия, адекватное господствующим центрам тяготения; 2) вызывает к жизни соответствующие изменения в своих отношениях с соседними региональными системами и общественно-хозяйственной системой страны.

Во второй половине XX века научнотехнический прогресс непосредственным образом отразился на практике ресурсопользования. Возникло понятие потенциальные ресурсы или «ресурсы будущего». Наиболее выдающиеся успехи были за теми, кто сумел использовать неосязаемые ресурсы, то есть знание, информацию, предпринимательскую способность, идеи, на базе которых создаются технологии, обеспечивающие ускоренное развитие человеческой цивилизации и дающие человеку все новые возможности удовлетворения своих неутолимых потребностей.

К знанию и информации применимы обычные экономические категории: производство, экономия на масштабе, конкуренция, спрос, предложение и экстерналии. Знания вытесняют на второй план традиционные экономические ресурсы - капитал, труд, природные ресурсы, отводя при этом все большую роль инновациям, под которыми теоретически прописываются ресурсы.

Считаем необходимым отметить несомненный для предшествующего столетия факт, если раньше наука развивалась в направлении углубления знаний на основе общественного разделения наук, то в предстоящее столетие должно произойти углубление знаний на основе их обобществления. Поэтому одной из главных задач современного общества является производство знаний и передача информации. В цивилизованных странах котируется преподавание, то есть передача знаний и опыта. Работник, занимающийся инновационной деятельностью, обладает так называемой метаквалификацией. И высшей целью общества становится процесс формирования и развития личности, развития способности воспринимать и осваивать новые знания в зависимости от количества и качества знаний, накопленных в прошлом.

Отметим, что проведенный анализ многочисленных профессиональных и научных исследований в различных областях экономической науки доказывает, что институты вносят значительный вклад в ускорение экономического развития и повышение качества экономического роста. Поэтому изучение институциональных основ ресурсного обеспечения инновационной деятельности имеет самостоятельное научное и практическое значение. 


\section{Заключение}

Все вышеуказанные и некоторые другие обстоятельства объективно выдвигают на первый план именно сейчас задачу более глубокого теоретического исследования ресурсов, играющих основную роль в создании инноваций в экономике, основанной на знаниях, а также уточнения адекватно современным реалиям их сущности, экономического содержания, форм, разновидностей, типов, проявлений, факторов формирования и реализации, способов измерения и оценки и других важных моментов. Причинами этого

\section{ЛИТЕРАТУРА}

1 Shenxue Li. Tapping the power of local knowledge: A local-global interactive perspective // Journal of World Business. T. 51, № 4, 2016, C. 641653. http://dx.doi.org/10.1016/j.jwb.2016.04.001

2 Стриженко А. Инновационность как фактор интенсивного экономического роста // Вестник Алтайской науки. 2015. № 2. С. 258-265.

3 Gaziulusoy A. Design for system innovations and transitions: a conceptual framework integrating insights from sustainability science and theories of system innovations and transitions Original Research Article // Journal of Cleaner Production, T. 108, № 1 2015, C. 558-568. http://dx.doi.org/10.1016/j.jclepro.2015.06.066

4 Зибров Г. В., Дедов С. В., Гордиенко Н. С., Демин С. В. Современная парадигма инновационных процессов // Вестник Воронежского государственного университета инженерных технологий. 2012. № 4. C. 171-174.

5 Дедов С. В. Направления институализации рынка инновационных ресурсов // Вестник ВГТА. 2011. № 4. C. 70-73.

\section{СВЕДЕНИЯ ОБ АВТОРАХ}

М. С. Асмолова соискатель, кафедра управления, организации производства и отраслевой экономики, Воронежский государственный университет инженерных технологий, пр-т Революции, 19, г. Воронеж, 394066, Россия, asmolova.m.s@gmail.com

С. В. Дедов соискатель, кафедра управления, организации производства и отраслевой экономики, Воронежский государственный университет инженерных технологий, пр-т Революции, 19, г. Воронеж, 394066, Россия, generdeser@bk.ru

\section{КРИТЕРИЙ АВТОРСТВА}

М. С. Асмолова обзор литературных источников по исследуемой проблеме

С. В. Дедов написал рукопись, корректировал её до подачи в редакцию и несёт ответственность за плагиат

\section{КОНФЛИКТ ИНТЕРЕСОВ}

Авторы заявляют об отсутствии конфликта интересов.

ПОСТУПИЛА 01.09.2016

ПРИНЯТА В ПЕЧАТЬ 11.11.2016 являются факторы, определяющие и активизирующие работу всех институтов государства [5]. Следовательно, базовые системы для ресурсного обеспечения инновационной деятельности становятся органичными элементами инновационной экономики, образуя общую конфигурацию хозяйственных отношений, позиционируют состав участников инновационных процессов по отношению друг к другу, в том числе и на региональном уровне. К настоящему времени в данном отношении еще много пробелов, проблем, разночтений и даже противоречий, поскольку широкого исследования не проводилось.

\section{REFERENCES}

1 Shenxue Li. Tapping the power of local knowledge: A local-global interactive perspective. Journal of World Business. V. 51, Issue 4, 2016, pp. 641653. http://dx.doi.org/10.1016/j.jwb.2016.04.001

2 Strizhenko A. Innovation as a factor of intensive economic growth. Vestnik Altaiskoi nauki [Proceedings of the Altai science]. 2015. no. 2. pp. 258-265. (in Russian).

3 Gaziulusoy A. Design for system innovations and transitions: a conceptual framework integrating insights from sustainability science and theories of system innovations and transitions. Original Research Article. Journal of Cleaner Production, V. 108, 2015, pp. 558-568. http://dx.doi.org/10.1016/j.jclepro.2015.06.066

4 Zibrov G. V., Dedov S. V., Gordienko N. S., Demin S. V. The modern paradigm of innovation processes. Vestnik VGUIT [Proceedings of VSUET]. 2012. no. 4. pp. 171-174. (in Russian).

5 Dedov S. V. The direction of institutionalization of the market of innovative resources. Vestnik VGTA [Proceedings of VGTA]. 2011. no. 4. pp. 70-73. (in Russian).

\section{INFORMATION ABOUT AUTHORS}

M. S. Asmolova applicant, management, organization of production and branch economy department, Voronezh state university of engineering technologies, Revolution Av., 19 Voronezh, 394066, Russia, asmolova.m.s@gmail.com

S. V. Dedov applicant, management, organization of production and branch economy department, Voronezh state university of engineering technologies, Revolution Av., 19 Voronezh, 394066, Russia, generdeser@bk.ru

\section{CONTRIBUTION}

M. S. Asmolova review of the literature on an investigated problem

S. V. Dedov wrote the manuscript, correct it before filing in editing and is responsible for plagiarism

\section{CONFLICT OF INTEREST}

The authors declare no conflict of interest.

RECEIVED 9.1.2016

ACCEPTED 11.11.2016 